(2) OPEN ACCESS

\title{
Recurrent giant cell tumour of the distal ulna after en bloc resection with preoperative denosumab use
}

\author{
Nasa Fujihara 두, Shunsuke Hamada, Masahiro Yoshida, Satoshi Tsukushi
}

Orthopaedic, Aichi Cancer Center, Nagoya, Aichi, Japan

Correspondence to

Dr Nasa Fujihara;

nfujihara@aichi-cc.jp

Accepted 12 October 2021

\section{SUMMARY}

In recent years, denosumab has been used to treat giant cell tumour of bone (GCTB) not only in cases where surgery is complicated but also preoperatively to decrease the preoperative grade or to facilitate surgery for Campanacci grade II and III cases. However, there are no clear protocols regarding the preoperative use of denosumab before en bloc resection. There are a few reports of recurrent cases after en bloc resection; however, the association with the use of denosumab is unknown. We present the clinical, radiological and histopathological findings of a case of Campanacci grade III GCTB at the distal end of the ulna, which resulted in soft tissue recurrence after en bloc resection with the preoperative use of denosumab.

\section{BACKGROUND}

Giant cell tumour of bone (GCTB) accounts for 20\% of benign bone tumours and is slightly more common in women aged $20-40$ years. Tumours often occur in the epiphysis and metaphysis of long bones, half of which are located around the knee. ${ }^{1}$

In the distal forearm, the distal radius is the most affected site, accounting for $10 \%$ of all GCTB cases, followed by GCTB of the ulna accounting for $3 \%-6 \%$; however, GCTB of the hand is relatively rare, accounting for $2 \%-3 \%$ of cases. ${ }^{23}$

Traditionally, the only treatment option for GCTB was surgery; however, after the approval by the Food and Drug Administration in 2013, denosumab has been more actively used as a medication for GCTB. Denosumab binds to and inhibits the receptor activator of nuclear factor-kappa B ligand; its ability to

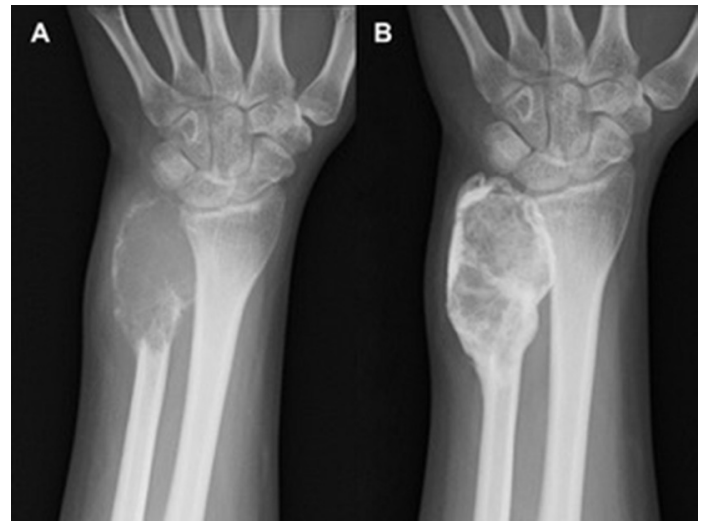

Figure 1 (A) Subarticular lytic expansile lesion of the distal ulna in the epiphysis and metaphysis showing a 'soap bubble appearance'. (B) After five injections of the oncology dose of denosumab, there is surrounding osteosclerosis and clarification of internal septations.
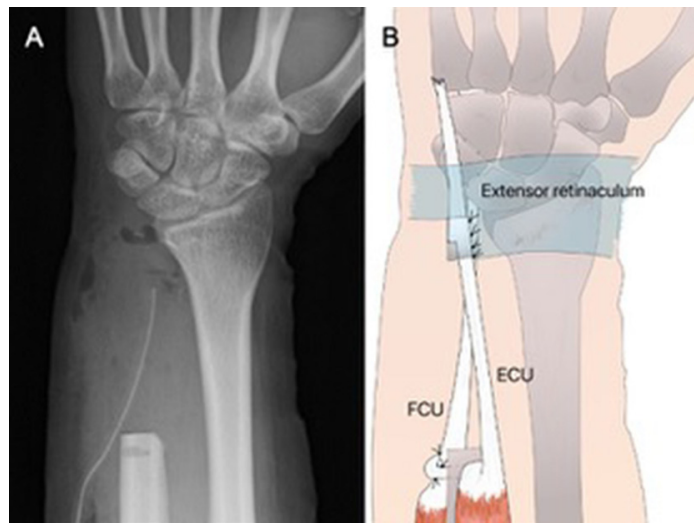

Figure 2 (A) Postoperative radiograph of the wrist after the first operation during which a $7 \mathrm{~cm}$ resection of the distal end of the ulna was performed. (B) The ECU tendon was cut into half and sutured to the flexor carpi ulnaris tendon through the bony hole of the ulnar end. The extensor retinaculum was partially inverted and sutured to the ECU tendon. This illustration was drawn by Nasa Fujihara. ECU, extensor carpi ulnaris; FCU, flexor carpi ulnaris.

reduce the formation and activation of osteoclasts has been effectively used for unresectable GCTB or preoperative downstaging of cases with extraskeletal extension. However, some of the recent evidence suggests that the preoperative use of denosumab is associated with higher postoperative recurrence in cases involving bone curettage; therefore, it should be used with caution. ${ }^{45}$ While there is no consensus on how to use denosumab when performing en bloc resection, a few case reports have suggested that it is suitable for clarifying the resection margin, thereby facilitating surgery.

In this study, we report a rare case of GCTB at the distal end of the ulna that developed soft tissue recurrence despite en bloc resection. Furthermore, we review the outcomes of distal ulna GCTB over the past 10 years during the denosumab era. The patient referenced in this case report provided written consent after being informed that all clinical data from the case would be submitted for publication. This study was approved by our institutional review board.

\section{CASE PRESENTATION}

A 26-year-old woman presented at our institution after experiencing progressive swelling and pain in the left wrist of her non-dominant hand over the previous 7 months. She had no history of trauma; however, the primary doctor diagnosed it as a postfracture condition. At a local clinic, the patient underwent observation for 3 months and was 


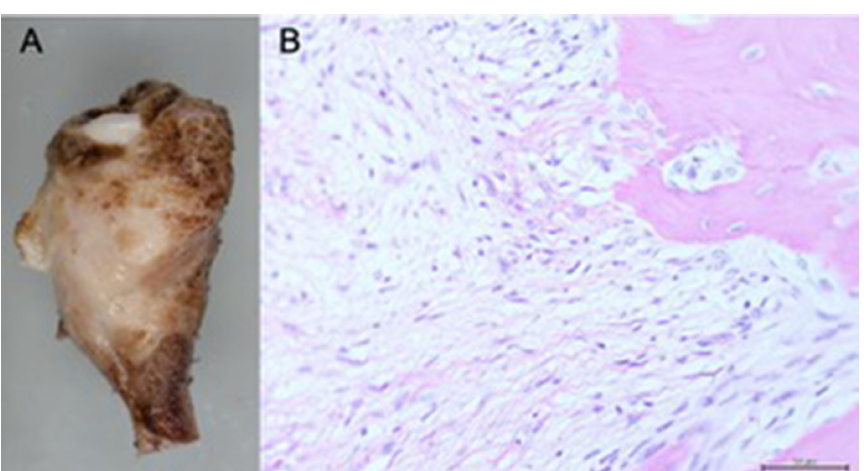

Figure 3 (A) Excised specimen. (B) Destruction of the osteoid and replacement with relatively loose fibrous tissues. There is increased fibrotic cell growth; variable giant cell tumour cells are absent (stain, $\mathrm{H} \& \mathrm{E}$; original magnification, $\times 40$ ).

prescribed painkillers without any rehabilitation or X-ray examination. During our initial examination, we observed that the patient exhibited a limited range of motion (ROM) in the wrist, with $45^{\circ}, 50^{\circ}, 90^{\circ}$ and $20^{\circ}$ of extension, flexion, pronation and supination of the forearm, respectively. She had severe pain on the ulnar side of her wrist joint; however, there was no numbness in her fingers. The blood test findings were normal, and the possibility of metabolic diseases, infection or osteomyelitis was considered to be low.

\section{INVESTIGATIONS}

Radiography (figure 1A) and MRI revealed an expansive Campanacci grade III osteolytic lesion. T1-weighted images showed low-signal to iso signal intensity, and T2-weighted images revealed heterogeneous high-signal and mixed low-signal areas due to haemosiderin and fibrosis. In addition, gadoliniumbased MRI scans showed prominent contrast effect, which is typical of GCTB. Incisional biopsy was performed using local anaesthesia, and a pathological diagnosis of GCTB was made.

\section{TREATMENT}

The patient was started on an oncology dose $(120 \mathrm{mg})$ of denosumab to reduce the tumour volume. Denosumab was administered with a 2 -week interval between the first and second doses

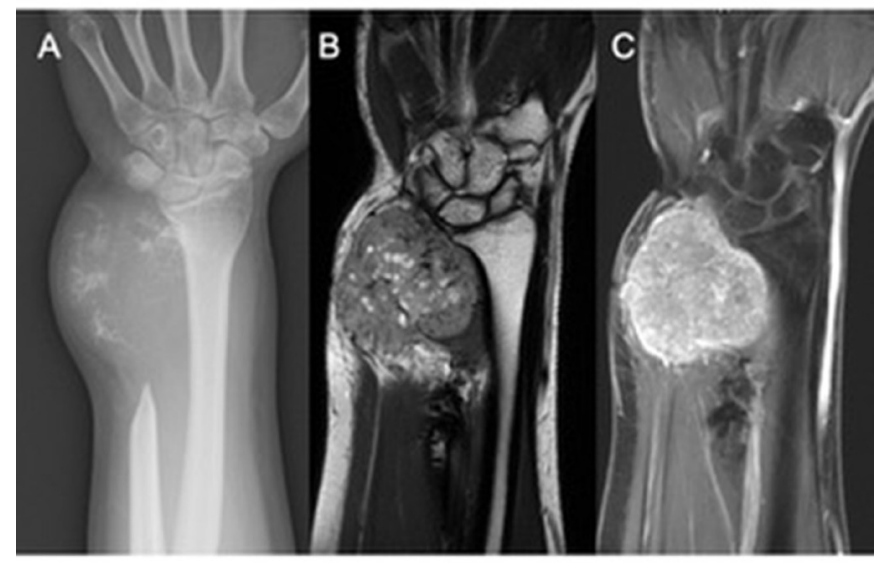

Figure 4 (A) Scattered calcifications and osteogenesis along the periosteum of the ulnar stamp. (B) T2-weighted MRI image shows high and low heterogeneous signal areas. (C) Recurrent soft tissue tumours display a prominent contrast effect.

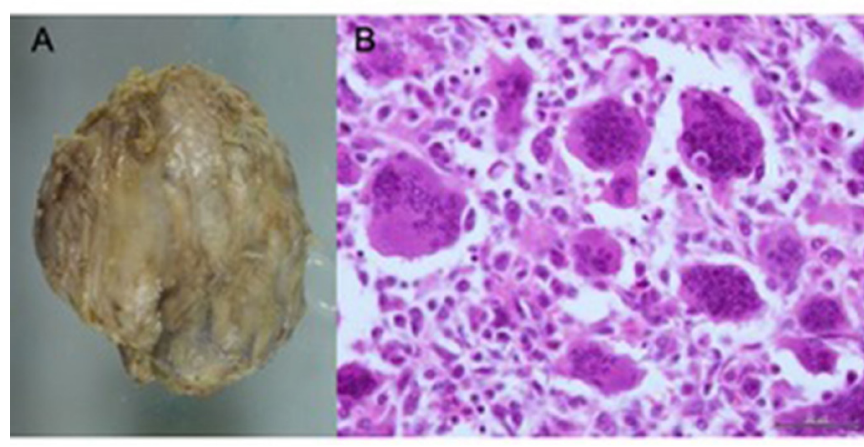

Figure 5 (A) Resected specimen during the second operation. (B) Mononuclear short spindle-shaped cells proliferated with multinucleated giant cells; osteogenesis is observed. There is no osteoid, and the patient is positive for H3.3G34W mutation-specific antibodies, consistent with the recurrence of giant cell tumour of bone. Vascular invasion is also present. Most tumours are viable giant cell tumour tissues (stain, H\&E; original magnification, $\times 40$ ).

and every 4 weeks thereafter for a total of five doses. After five injections of denosumab, the patient's wrist pain resolved and the ROM improved to $60^{\circ}$ of supination, $60^{\circ}$ of dorsal flexion and $70^{\circ}$ of volar flexion. X-ray imaging revealed tumour shrinkage and osteosclerosis of the margins (figure 1B).

Surgical resection was performed under general anaesthesia 5 months after the first presentation. En bloc bone resection and ulnar stabilisation were performed using the extensor carpi ulnaris (ECU) tendon because the original tumour was Campanacci grade III, which has a high reported rate of local recurrence, particularly in areas where it is difficult to perform curettage treatment, such as the distal forearm or finger bones. A portion of the ulna, measuring $7 \mathrm{~cm}$, was resected. The ECU tendon was cut into half at the distal end, passed through a hole at the end of the ulna and fixed to the flexor carpi ulnaris tendon. Subsequently, the extensor retinaculum was partially inverted and sutured to the ECU tendon to stabilise the ulnar bone (figure 2).

In the final pathological evaluation, no variable cells were detected in the resection specimen, suggesting that denosumab had been fully effective (figure 3). However, 22 months after the initial surgery, the patient again experienced swelling on the ulnar side of the left wrist joint, which was left untreated because of her work schedule.

She presented at the hospital with an obvious mass-like lesion at 27 months after the first surgery. The X-ray imaging revealed scattered calcification at the margins, indicating soft tissue recurrence. MRI revealed the recurrence of an oval-shaped tumour measuring $6 \mathrm{~cm}$ in the soft tissues of the distal ulna, with an internal signal similar to that of a GCTB-low T1 and iso signal to high T2 signal. In addition, the tumour displayed a contrast effect, similar to that of a GCTB (figure 4). CT was also performed to check for lung metastases, which revealed no distant metastases.

After five additional denosumab injections, marginal resection was performed. The surrounding soft tissues of the ECU tendon were scarred and sclerotic, whereas the remaining ulnar fragment was stable after resection; therefore, a simple resection was adequate. Postoperative pathological evaluation revealed a consistent recurrence of GCTB and variable tumour cells (figure 5), suggesting that the second set of denosumab injections might not have been as effective as the first. 


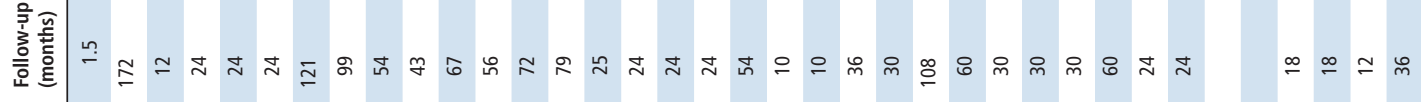

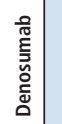

$\stackrel{\circ}{\frac{\Xi}{2}}$

產

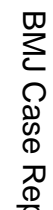

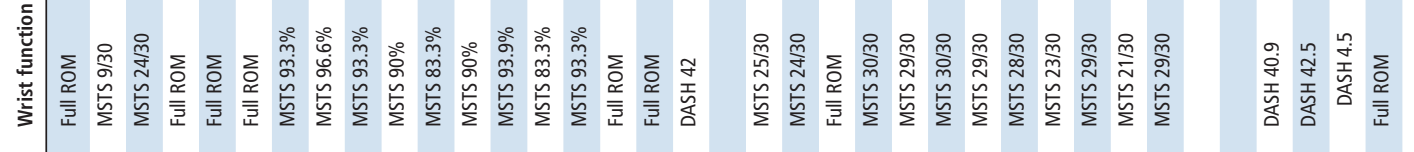

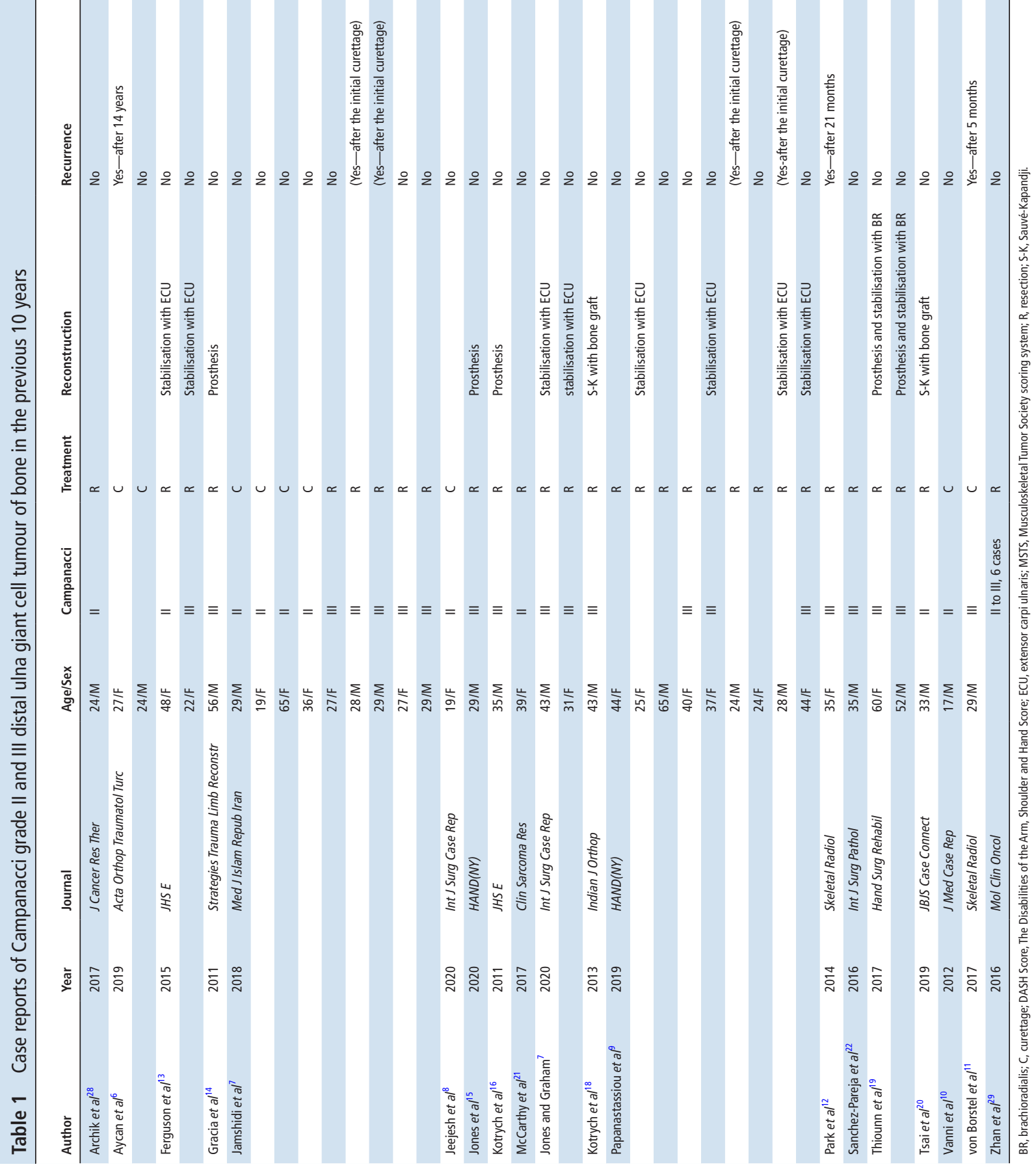




\section{OUTCOME AND FOLLOW-UP}

There was no evidence of tumour recurrence or worsening of the ROM of the wrist at a year after the second surgery.

\section{DISCUSSION}

There is no established treatment for Campanacci grade II and III distal ulnar GCTB; nevertheless, en bloc resection has been the empirical choice to prevent tumour recurrence unless the patient specifically asks to preserve his or her joints. A review of the literature of the past 10 years since denosumab was first clinically used revealed that there were 19 reports describing 44 cases of Campanacci grade II and III distal ulnar GCTB (table 1).

In 13 cases, bone curettage was performed in the initial surgery, ${ }^{6-11}$ in which at least three were grade III cases. However, there was local recurrence in all grade III cases, ${ }^{71}$ suggesting that en bloc resection is necessary in such conditions. Among the patients who underwent en bloc resection in the first surgery, only one exhibited local recurrence; this was a soft tissue recurrence, as noted in the present case. ${ }^{12}$ Tendons or implants were used for reconstruction in 15 cases $(15 / 35,42.9 \%),{ }^{9} 13-20$ and all these cases exhibited favourable postoperative results. The most common method for stabilisation of the ulnar stump is using the ECU tendon. ${ }^{9}{ }^{13} 17$ In three studies, prosthetic reconstruction with implant arthroplasty of the distal radioulnar joint was reported, ${ }^{14-16}$ while reconstruction of the distal radioulnar joint using an iliac bone block and screws-a modification of the Sauvé-Kapandji procedure-was reported in two studies. ${ }^{18-20}$ Ferguson $e t a l^{13}$ and Papanastassiou et $a l^{9}$ reported that reconstruction was not essential based on case comparisons of their own studies. In fact, in more than half of the reviewed cases, no reconstruction was performed, and almost all obtained favourable results (average Musculoskeletal Tumor Society scoring system score: $88.7 \%$, range 30\%-100\%). Although the indication remains controversial, unlike in cases of trauma, reconstruction of the distal ulnar portion may not be mandatory in cases of slow-growing tumours if the tumour size is relatively small. However, considering that in most cases there was no long-term follow-up, we believe that it is better to consider reconstruction, particularly in younger patients when the disadvantages of reconstruction are not significant. In the present case, we obtained favourable results by resecting $7 \mathrm{~cm}$ (distal one-third portion) of the ulna and reconstructing it using the ECU tendon, which is the most common reconstruction method.

Denosumab was used as a preoperative adjuvant in three cases $(3 / 45,6.7 \%) .^{112122}$ In all cases, denosumab was used in the same dosage and manner $(120 \mathrm{mg}$ every 4 weeks with additional loading doses of $120 \mathrm{mg}$ on days 8 and 15 of the first month) for 3-6 months. In addition, denosumab was used only preoperatively in all three cases. There were no reports of decreased efficacy when used at the time of recurrence, as in this case. McCarthy et $\mathrm{al}^{21}$ described the effects of a short preoperative course of denosumab on distal forearm GCTB, and all patients experienced some pain relief after initiating denosumab. They suggested that the origin of pain may be multifactorial, including mechanical stress from tumour-related pressure, expansion of the periosteum, loss of structurally significant bone and mechanical failure. In addition, the production of prostaglandins, endothelin and other noxious factors by the tumour itself is known to cause pain. Similar to that report, in our case, shortterm preoperative denosumab use resulted in pain alleviation and improvement in ROM of the wrist. Sanchez-Pareja $e a^{22}$ reported that a slight tumour enlargement was observed immediately after denosumab use. Although there was some concern regarding sarcomatous changes, they ultimately concluded that the changes were a reactive phenomenon. In our case, osteosclerosis was observed, as reported in other studies, ${ }^{21} 22$ which might have facilitated the removal of the tumour but did not reduce its size.

A recent review of the preoperative use of denosumab in treating $\mathrm{GCTB}^{5}$ suggests that it should be avoided owing to the risk of tumour cells getting trapped in the sclerotic bone cortex and that bone curettage is the treatment of choice. However, there is no definitive indication regarding its use when en bloc resection is performed. ${ }^{423}$ In our case, the sclerosis of the mass edges and the degree of swelling that reduced the patient's pain and ROM restriction proved advantageous and facilitated surgical resection; however, soft tissue recurrence was a disadvantage. It is possible that dormant tumour cells that remained in the soft tissues could have been activated when denosumab was discontinued after the surgery. $^{24}$

Given the effect of denosumab on the tumour, it may be necessary to continue its use as adjuvant therapy even after surgery; however, evidence on the safety of long-term denosumab use in young patients has not been established. ${ }^{24} 25$ Furthermore, a previous report discussed a rare case wherein sarcomatous changes were observed after denosumab use. ${ }^{26}$ Therefore, the effects of long-term use of denosumab in young patients with GCTB require further investigation, and more case studies are necessary. Furthermore, there is no report that denosumab use could contribute to soft tissue recurrence. Tumour recurrence in the soft tissues after en bloc resection itself is rare $(1.5 \%-3.1 \%) .{ }^{27}$ It is also possible that there are consequences to denosumab discontinuation; nevertheless, details of the pharmacological effects are unknown.

In summary, we report a rare case of distal ulnar GCTB where soft tissue recurrence occurred despite performing en bloc resection. A review of the literature revealed that patients with grade III distal ulnar GCTB require at least en bloc resection; however, reconstruction may not be mandatory in some cases. Preoperative denosumab use alone may be insufficient to achieve acceptable oncological outcomes. It is also possible that denosumab may be less effective at the time of tumour recurrence. The duration and appropriate dose of denosumab should be investigated in future research.

\section{Learning points}

- This is a rare case of giant cell tumour of bone wherein the patient developed soft tissue recurrence despite undergoing en bloc resection.

- It is unclear whether the use of denosumab affected the soft tissue recurrence.

- The therapeutic effect of denosumab at the time of recurrence was possibly poor.

Twitter Nasa Fujihara @fujinasa

Contributors ST provided supervision. The patient was under the care of ST and NF. The report was written by NF, SH and MY. Figure 2B was created by NF.

Funding The authors have not declared a specific grant for this research from any funding agency in the public, commercial or not-for-profit sectors.

Competing interests None declared.

Patient consent for publication Consent obtained directly from patient(s)

Provenance and peer review Not commissioned; externally peer reviewed.

Open access This is an open access article distributed in accordance with the Creative Commons Attribution Non Commercial (CC BY-NC 4.0) license, which permits others to distribute, remix, adapt, build upon this work non-commercially, and license their derivative works on different terms, provided the original work is properly cited and the use is non-commercial. See: http://creativecommons.org/ licenses/by-nc/4.0/.

\section{ORCID iD}

Nasa Fujihara http://orcid.org/0000-0002-4197-0586 


\section{REFERENCES}

1 Hakim DN, Pelly T, Kulendran M, et al. Benign tumours of the bone: a review. J Bone Oncol 2015;4:37-41.

2 Verschoor AJ, Bovée JVMG, Mastboom MJL, et al. Incidence and demographics of giant cell tumor of bone in the Netherlands: first nationwide pathology registry study. Acta Orthop 2018;89:570-4.

3 Biscaglia R, Bacchini P, Bertoni F. Giant cell tumor of the bones of the hand and foot. Cancer 2000:88:2022-32.

4 Urakawa H, Yonemoto T, Matsumoto S, et al. Clinical outcome of primary giant cell tumor of bone after curettage with or without perioperative denosumab in Japan: from a questionnaire for JCOG 1610 study. World J Surg Oncol 2018;16:160.

5 Yayan J. Denosumab for effective tumor size reduction in patients with giant cell tumors of the bone: a systematic review and meta-analysis. Cancer Control 2020;27:107327482093482.

6 Aycan OE, Sökücü S, Özer D, et al. Primary bone tumors and tumor like lesions of the ulna. Acta Orthop Traumatol Turc 2019:53:30-4

7 Jamshidi K, Bahrabadi M, Bagherifard A, et al. Surgical treatment outcome of giant cell tumor of distal ulna: en bloc resection vs. curettage and bone graft. Med J Islam Repub Iran 2018:32:249-53.

8 T K JK, Pai PK, Rajasubramanya P. Two rare cases of giant cell tumor of distal ulna. Int J Surg Case Rep 2020;76:474-9.

9 Papanastassiou ID, Savvidou OD, Chloros GD, et al. Extensor carpi ulnaris tenodesis versus no stabilization after wide resection of distal ulna giant cell tumors. Hand 2019:14:242-8.

10 Vanni D, Pantalone A, Andreoli E, et al. Giant cell tumor of the distal ulna: a case report. J Med Case Rep 2012;6:143.

11 von Borstel D, A. Taguibao R, A. Strle N, et al. Giant cell tumor of the bone: aggressive case initially treated with denosumab and intralesional surgery. Skeletal Radiol 2017:46:571-8.

12 Park S-Y, Lee MH, Lee JS, et al. Ossified soft tissue recurrence of giant cell tumor of the bone: four case reports with follow-up radiographs, CT, ultrasound, and MR images. Skeletal Radiol 2014;43:1457-63.

13 Ferguson KB, Jane M, Mahendra A. Giant cell tumour of the distal ulna: is reconstruction required after excision of the distal third of the ulna? J Hand Surg Eur Vol 2016:41:771-2.

14 Gracia I, Proubasta IR, Trullols L, et al. Distal radioulnar joint prosthesis for the treatment of giant cell tumor of the distal ulna: a case report and literature review. Strategies Trauma Limb Reconstr 2011;6:103-6.
15 Jones NF, Graham DJ. Radical resection of a recurrent giant cell tumor of the distal ulna and immediate reconstruction with a distal radio-ulnar joint implant arthroplasty. HAND 2020;15:NP68-72.

16 Kotrych D, Żyluk A, Walaszek I. Reconstruction of the distal radioulnar joint with a prosthesis after excision of a recurrent giant-cell tumour of the distal ulna. J Hand Surg Eur Vol 2011;36:428-30.

17 Jones NF, Graham DJ. Radical resection of a recurrent giant cell tumor of the distal ulna and immediate reconstruction with a distal radio-ulnar joint implant arthroplasty. Hand 2020;15:NP68-72.

18 Kotrych D, Zyluk A, Walaszek I. Reconstruction of the distal radioulnar joint with a prosthesis after excision of a recurrent giant-cell tumour of the distal ulna. $J$ Hand Surg Eur Vol 2011;36:428-30.

19 Thiounn A, Guerre E, Szymanski C, et al. Two cases of distal ulna giant cell tumors treated by extensive resection, prosthetic reconstruction and stabilization using the brachioradialis tendon. Hand Surg Rehabil 2017:36:419-22.

20 Tsai T-C, Chen C-C, Huang H-K, et al. Modified Sauve-Kapandji procedure using iliac bone graft for giant cell tumor of the distal ulna: stabilizing with two-screw fixation: a case report. JBJS Case Connect 2019;9:e0299.

21 McCarthy CL, Gibbons CLMH, Bradley KM, et al. Giant cell tumour of the distal radius/ ulna: response to pre-operative treatment with short-term denosumab. Clin Sarcoma Res 2017;7:19.

22 Sanchez-Pareja A, Larousserie F, Boudabbous S, et al. Giant cell tumor of bone with pseudosarcomatous changes leading to premature denosumab therapy interruption: a case report with review of the literature. Int I Surg Pathol 2016:24:366-72.

$23 \mathrm{Li} \mathrm{H,} \mathrm{Gao} \mathrm{J,} \mathrm{Gao} \mathrm{Y,} \mathrm{et} \mathrm{al.} \mathrm{Denosumab} \mathrm{in} \mathrm{giant} \mathrm{cell} \mathrm{tumor} \mathrm{of} \mathrm{bone:} \mathrm{current} \mathrm{status} \mathrm{and}$ pitfalls. Front Oncol 2020;10:580605.

24 Tsourdi E, Langdahl B, Cohen-Solal M, et al. Discontinuation of denosumab therapy for osteoporosis: a systematic review and position statement by ECTS. Bone 2017; 105:11-17.

25 Dempster DW, Brown JP, Fahrleitner-Pammer A, et al. Effects of long-term denosumab on bone histomorphometry and mineralization in women with postmenopausal osteoporosis. J Clin Endocrinol Metab 2018;103:2498-509.

26 Aponte-Tinao LA, Piuzzi NS, Roitman P, et al. A high-grade sarcoma arising in a patient with recurrent benign giant cell tumor of the proximal tibia while receiving treatment with denosumab. Clin Orthop Relat Res 2015:473:3050-5.

$27 \mathrm{Xu} \mathrm{L}$, Jin J, Hu A, et al. Soft tissue recurrence of giant cell tumor of the bone: prevalence and radiographic features. J Bone Oncol 2017:9:10-14.

28 Archik S, Tripathi SK, Nanda SN, et al. Giant cell tumour of distal ulna. J Cancer Res Ther 2017:13:586-8.

29 Zhang J, Li Y, Li D, et al. Clinical effects of three surgical approaches for a giant cell tumor of the distal radius and ulna. Mol Clin Oncol 2016:5:613-7.

Copyright 2021 BMJ Publishing Group. All rights reserved. For permission to reuse any of this content visit https://www.bmi.com/company/products-services/rights-and-licensing/permissions/ BMJ Case Report Fellows may re-use this article for personal use and teaching without any further permission.

Become a Fellow of BMJ Case Reports today and you can:

- Submit as many cases as you like

Enjoy fast sympathetic peer review and rapid publication of accepted articles

Access all the published articles

Re-use any of the published material for personal use and teaching without further permission

Customer Service

If you have any further queries about your subscription, please contact our customer services team on +44 (0) 2071111105 or via email at support@bmj.com.

Visit casereports.bmj.com for more articles like this and to become a Fellow 